\title{
Women's Sexual Health in COVID-19 Pandemic: Challenges and Solutions
}

\author{
Mahmoudreza Peyravi; ${ }^{1}$ (1) Ahmad Soltani; ${ }^{2,3}$ Milad Ahmadi Marzaleh ${ }^{2,3,4,5,6}$ (1)
}

Note: Mahmoudreza Peyravi and Ahmad Soltani have had the same contribution and both are first author.

1. Assistant Professor, Department of Health in Disasters and Emergencies, Health Human Resources Research Center, School of Management and Medical Informatics, Shiraz University of Medical Sciences, Shiraz, Iran

2. Assistant Professor, Research Center for Emergency and Disaster Resilience, Red Crescent Society of the Islamic Republic of Iran, Tehran, Iran

3. Assistant Professor, Iran-Helal Institute of Applied-Science and Technology, Red Crescent Society of the Islamic Republic of Iran, Tehran, Iran

4. Assistant Professor, Research Center for Health Management in Mass Gathering, Red Crescent Society of the Islamic Republic of Iran, Tehran, Iran

5. $\mathrm{PhD}$ of Health in Disasters and Emergencies, Student Research Committee, Department of Health in Disasters and Emergencies, Health Human Resources Research Center, School of Management and Medical Informatics, Shiraz University of Medical Sciences, Fars, Iran

6. MPH of Health Policy, Health Policy Research Center, Institute of Health, Shiraz University of Medical Sciences, Fars, Iran

\author{
Correspondence: \\ Milad Ahmadi Marzaleh \\ Assistant Professor \\ Research Center for Health Management in \\ Mass Gathering \\ Iran-Helal Institute of Applied Science \\ and Technology \\ Red Crescent Society of the Islamic \\ Republic of Iran \\ Tehran, Iran \\ E-mail: miladahmadimarzaleh@yahoo.com
}

Conflicts of interest: The authors have no conflict of interest to declare.

Keywords: coronavirus; COVID-19; health; pandemic; sexual health; woman

Peyravi M, Soltani A, Ahmadi Marzaleh M. Women's sexual health in COVID-19 pandemic: challenges and solutions. Prehosp Disaster Med. 2020;35(6):698-699.

Dear Editor,

The first case of COVID-19 was reported in Wuhan, China's Hubei Province in December 2019. ${ }^{1}$ COVID-19 is very contagious and features a very high risk of infectiousness and outbreak. Considering its rapid pandemic world-wide, a global public health emergency condition was declared by the World Health Organization (WHO; Geneva, Switzerland)

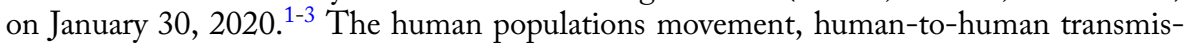
sion, and environmental factors can lead to the spread of this virus. The most common clinical symptoms of this virus include fever, cough, headache, muscular spasm, and fatigue. ${ }^{4}$ Furthermore, females have been more vulnerable to the disease compared to males at the time of the COVID-19 epidemic.

Sexual behaviors include a vast spectrum of activities, with girls and women being amongst the susceptible groups. The COVID-19 pandemic has had many subtle effects on health care. In addition, social distancing can be followed by numerous consequences for individuals' relations and women's sexual life, including the frequency and tendency towards sexual relations. Generally, stressful conditions exert different effects on individuals' sexual lives, occasionally causing an increase or a decrease in the frequency of and tendency towards sexual relations. Unlike such disasters as earthquake and war wherein houses are destroyed, individuals have had more opportunities for being together at home during the COVID-19 quarantine. Thus, this group's vulnerability has been augmented. However, the possibility of vaginal infection has been reduced due to remaining at home, observing hygiene, and following ethical issues due to social distancing. The likelihood of not doing high-risk sexual behaviors has increased as well. The forthcoming section deals with the challenges and solutions that can enhance women's sexual health during the COVID-19 pandemic.

At the time of the COVID-19 pandemic, women are faced with the following sexual challenges: (1) sexual violence and misuse due to the marital conflicts stemming from quarantine and long periods of the whole family staying together; (2) constant need for taking care of children that lowers the women's chance of taking care of themselves; (3) issues like losing one's health and job, being away from one's family, and lack of social and familial communication that cause psychological consequences, leading to change in sexual behaviors; (4) relative cessation and/or offering no contraceptive methods, including intrauterine device/IUD insertion by obstetrical clinics and obstetricians due to observation of health care standards; (5) fear from COVID-19 transmission in the course of sexual relations; (6) not considering the health care and special sexual needs of the women with HIV and other viral diseases in the list of priorities; (7) taking no care of prostitutes' special needs; (8) menstrual disorders, especially amenorrhea; (9) increase in sexual activities due to staying at home for a longer time; (10) disorder in the tendencies towards women's pregnancy due to the inappropriateness of the future conditions after COVID-19; (11) further limitation of

Received: July 20, 2020

Accepted: August 3, 2020

\section{doi:10.1017/S1049023X20001107}

(C) The Author(s), 2020. Published by Cambridge University Press on behalf of World Association for Disaster and Emergency Medicine. This is an Open Access article, distributed under the terms of the Creative Commons Attribution-
NonCommercial-NoDerivatives licence (http:// creativecommons.org/licenses/by-nc-nd/4.0/), which permits non-commercial re-use, distribution, and reproduction in any medium, provided the original work is unaltered and is properly cited. The written permission of Cambridge University Press must be obtained for commercial re-use or in order to create a derivative work. 
access to health care tools, including women's sanitary pads; (12) reduction in the quality of sexual relations, especially among women; (13) potential risk of constant utilization of alcohol and antiseptics on women's reproductive system; (14) existence of sexual taboos, especially in eastern communities; (15) giving up the sexual desires of one's partner and/or husband under any conditions; (16) influence on access to contraception methods during the pandemic, causing a lot of unwanted pregnancies and lack of adequate care during pregnancy; (17) reduction in the tendency towards pregnancy for such reasons as the possible impact of the virus on the fetus, worries about access to ordinary health care services during pregnancy, and economic concerns; (18) increase in sexual tensions and tendencies among women; (19) specific health care issues among lesbians; (20) sexual arousal due to the lack or reduction of sexual intercourse during the COVID-19 pandemic; (21) social distancing risk factors; (22) growth of sexual exploitation by groups and gangs from women around the world; and (23) increase in unwanted abortions.

The following solutions and strategies are suggested for enhancing women's sexual health: (1) considering women and men as social groups with different needs and priorities during pandemics; (2) fast diagnosis and treatment of the cases of sexual abuse; (3) consultation and performance of screening for cervical cancer; (4) observing health care issues during sexual relations; (5) establishing visits and online, telephone-based, and messagebased visiting services specific to women; (6) offering purposive protocols and teachings to both the general public and service providers; (7) providing general public's access to emergency services during the quarantine and establishing a hot line for reporting the cases of familial and sexual violence; (8) codifying supportive and protective packages by the governments; (9) instructing measures for promotion of women's sexual health; (10) participation in family health counseling sessions or consultation with midwifery and family health professionals; (11) having free, easy, and continuous access to contraceptives and hygiene products; (12) expressing women's sexual desires and improving husbands' logical and healthy interactions; (13) increasing men's knowledge and awareness about problems and promoting women's sexual health; (14) making international and national efforts to eliminate harmful sexual taboos in eastern communities; and (15) developing healthy sexual communication protocols during pandemics.

\section{Conclusion}

Given the pandemic and daily increasing expansion of COVID-19 world-wide, paying special attention to women's health is of vital importance. Women have been considered among the sensitive groups and are consequently in need of special care. Sexual health care programs and guidelines for women should be codified in global, national, and local levels. Thus, health care policymakers are recommended to develop special protective programs for supporting women and girls so as to protect and enhance their health as well as the health of their families and the community during the COVID-19 pandemic.

\section{Acknowledgement}

The authors would like to thank Ms. A. Keivanshekouh at the Research Improvement Center of Shiraz University of Medical Sciences (Shiraz, Iran) for improving the use of English in the manuscript.

\section{References}

1. Huang C, Wang Y, Li X, et al. Clinical features of patients infected with 2019 novel coronavirus in Wuhan, China. Lancet. 2020;395(10223):497-506.

2. Zhu N, Zhang $\mathrm{D}$, Wang $\mathrm{W}$, et al. A novel coronavirus from patients with pneumonia in China, 2019. N Engl J Med. 2020;382(8):727-733.

3. Chen N, Zhou M, Dong X, et al. Epidemiological and clinical characteristics of 99 cases of 2019 novel coronavirus pneumonia in Wuhan, China: a descriptive study. Lancet. 2020;395(10223):507-513. 4. Wang W, Tang J, Wei F. Updated understanding of the outbreak of 2019 novel coro-
navirus (2019-nCoV) in Wuhan, China. J Med Virol. 2020;92(4):441-447. 